\title{
Utilizing an ANP framework for prioritizing effective criteria on industrial clusters' formation
}

\author{
Jalal Haghighat Monfared ${ }^{\mathrm{a}}$, Hossein Jannatifar ${ }^{\mathrm{a}}$ and Javad Siahkali Moradi ${ }^{\mathrm{a}^{*}}$
}

${ }^{a}$ Department of Management, Islamic Azad University, Central Tehran branch, Tehran, Iran

${ }^{b}$ Master of Operations Management, Central Branch, Islamic Azad University, Tehran, Iran

${ }^{c}$ Master of Operations Research, Department of Management and Economy, Science and Research Branch, Islamic Azad University, Tehran, Iran

\begin{tabular}{|c|c|}
\hline A R T I C L E I N F O & A B S T R A T \\
\hline $\begin{array}{l}\text { Article history: } \\
\text { Received October 10, } 2011 \\
\text { Received in Revised form } \\
\text { November, } 14,2011 \\
\text { Accepted } 28 \text { November } 2011 \\
\text { Available online } \\
9 \text { December } 2011 \\
\text { Keywords: } \\
\text { Industrial Clusters } \\
\text { Economic Growth } \\
\text { Analytical Network Process }\end{array}$ & $\begin{array}{l}\text { Clustering plays an important role on developing industries, since business units can take } \\
\text { advantage of many existing industries for trouble shooting or sharing their experiences to } \\
\text { increase efficiency. One of the primary concerns for developing clustering is to identify and } \\
\text { remove important barriers. In this paper, we gather experts' feedbacks on forming clustering in } \\
\text { Iran's industries and, using analytical network process, we prioritize the important factors and } \\
\text { provide some necessary guidelines to develop clustering. The results of this paper indicate that } \\
\text { the existence of a supplier network is the most important factor, followed by the existence of } \\
\text { competition between operational units, existence of high-risk investors, existence of suitable } \\
\text { infrastructures. There are also other less important criteria including the existence of flexibility, } \\
\text { suitable technology and competition, governmental regularities, social background, trust, etc. }\end{array}$ \\
\hline
\end{tabular}

\section{Introduction}

During the past few decades, there have been different attempts to increase the productivity of plants by agglomerating them. This normally helps various similar units of production plants to benefit the economy of scale. There are many advantages of agglomerating firms since firms have the access to greater specialization, multiple suppliers with higher competition and division of labor result. Clustering could also happen when multiple firms in the same sector form a cluster and they absorb more suppliers and customers than a single firm can do. The term of clustering is also associated with economies of scale and it is important to implement clustering when the advantages are reasonably attractive. Agglomeration economies could lead to formation and growth of cities and there are factors, which must contribute to the formation and growth of cities. A comprehensive growth in all factors influencing clustering economy could lead to a successful clustering (Nadvi, 1994; Boari, 2001; Porter, 1985-2003).

\footnotetext{
* Corresponding author. Tel.: +989122520885

E-mail addresses: syahkaly@yahoo.com (J. Siahkali Moradi) 
There are different advantages associated with clustering industries and business units form clusters of economic activity. An immediate advantage is that there are specific development strategies, which flow in and throughout this area of economic activity. As a result, there is an accumulation of some of the necessary information and innovative ideas among various production units, which leads to increase return to scale. Another advantage of having a clustered unit is that there is a fixed or average cost of production for production plans based on suppliers' requirements, labor, capital, etc. The existence of competitive cost components indicates a presence of economies of scale and increased total output of a product. Agglomeration economies will eventually contribute to growth of cities and economy and urbanize areas as well (Altenburg \& Meyer-Stamer, 1999).

Despite the fact that there are many advantages associated with clustering industry, there are also some disadvantages of clustering. Agglomeration economies may also lead to congestion, pollution and other negative factors created by the clustering of a population of firms and people, which eventually could lead to diseconomies of scale. Big cities experience such issues, and it is the tension between agglomeration economies and agglomeration diseconomies, which could contribute to the growth of the area, control the growth of the area, or reduce the growth of economy. Therefore, we need to maintain a stable outcome for agglomeration economies by clustering to create "knowledge spillovers" to reduce these negative externalities. Different countries normally have various experiences in terms of clustering economies (Scott, 1996).

It nearly takes three decades until we see actual results of clustering industries in terms of income distribution, productivity, etc. Industrial clusters is defined as suitable pattern for industrial advancement through divisions of specialized activities, cooperation between industries, interactive learning and other affairs, which are essential for industries' competition. The idea of clustering industries has had an old history. According to Schmitz and Nadvi (1999), the primary issue of industrial clusters has gone back from more than one thousand years ago. Industrial clusters are usually formed as a group of agencies and economic and non-economic institutes being related as horizontal and vertical forms, cooperated and competed with each other.

For instance, common orders, usage of common distribution networks, technological relationships, common research areas, common educational backgrounds, common education of managers, standards, common markets, orders of common usable technologies and usage of common working market backgrounds like stock constitution of common human being capital (Enright, 1996). According to Schmitz (1995), clustering facilities achievement of human and financial resources, it could reduce the risk of production, it could help small companies grow faster and it could gather the necessary skills and capital.

In this paper, we present an empirical study to measure the relative importance of different factors influencing clustering industries. The orientation of this paper first discusses the history of clustering industries along with some of the important factors in section 2. Section 3 discusses the priorities of these factors and concluding remarks are given in the last section to summarize the contribution of the paper.

\section{Clustering industries}

Despite the fact that there are literally several best practices of clustered regions in the world, we may not conclude that all attempts are successful. For instance, the first attempt to establish industrial districts in Iran was utilized about 40 year ago in the city of Karaj, but lack of knowledge, wisdom and experiences prevented the process of establishing the industrial district. Since the case study of our proposed model is associated with Iran, we briefly discuss the history in this section. United Nations initiated the idea of industrial districts in Iran during the years of 60st and after 5 years, this industrial district was established subsequent to expertly assessment of United Nations consultant in 
small industries, economic expert of plan organization and fulfillment of measurable probability studies. Some of the well know industrial towns during the early years of the proposed idea are as follows,

- Industrial districts of Alborz, year of establishment 1969;

- Industrial districts of Kermanshah, year of establishment 1971;

- Industrial districts of Kaveh, year of establishment 1973;

- Industrial districts of Rasht, year of establishment 1974.

During the past three decades, principle agreeable holders were in relation in order to establish industrial units with different organizations like natural resources, water, electricity, gas, telephone and due to lack of coordination among the aforesaid organization, some problems were emerged in establishing relations brought about wandering industrial units. In addition, protection of environment, prevention of pressure and pollution were the problems that should be attended them more. Presently, over 30 provinces of Iran enjoy the benefits of the idea of industrial district.

\subsection{The proposed industrial cluster distinct}

Theoretical principles of industrial clusters and operational indexes emphasize on factors, which are effective in constitution and operation of cluster. Meaning provision of one or some limited factor does not answer jurisdiction about the quality of activities including clustering potential and should assess all factors.

\subsubsection{Domestic factors}

Industrial regions are defined as social-territorial nature and economical context. Therefore, space is considered as an important factor, which makes complex constituted network of local relationships among economical factors. This local network includes common district among factors and determines its domination. Therefore, geographical closeness is associated with part specialization in industrial districts.

\subsubsection{Social and cultural factors}

It is necessary to say that social characteristics are necessary for the operation of industrial district. In industrial districts, organization is compounded with existing social relationships and social behavior complying with norms and social structures. Hence, social rules effect on deal methods and communication ways between employees, employers and economic factors pertained to that society. Meaning social coherency or common social origins of employers are effective in the birth of behavioral principle. This behavioral principle remarks existence of behavioral and economic prohibition executing in opportunistic behavior (Pyke, 1992; Rabellotti 1997; Rabellotti, \& Schmitz, 1993).

\subsubsection{Political and organic factors}

Governments can interfere differently in terms of posing new legal or financial regulations. Some regions could benefit out of new regulations and some may lose their privileges due to some environmental conditions.

\subsubsection{Organizational factors}

There are other organizational factors, which could restrict some firms on being active in some regions. Human resource limitations, access to raw materials, etc. are some the related factors, which must be considered. 


\subsubsection{Economic factor}

It is important to know that the existence of some similar production units in a particular region could reduce the cost of production for other companies by acting as reliable suppliers, which reduces the cost of transportation, significantly. Based on the criteria discussed, we consider some other subcriteria and details of our proposed hierarchy process is summarized in Fig. 1.

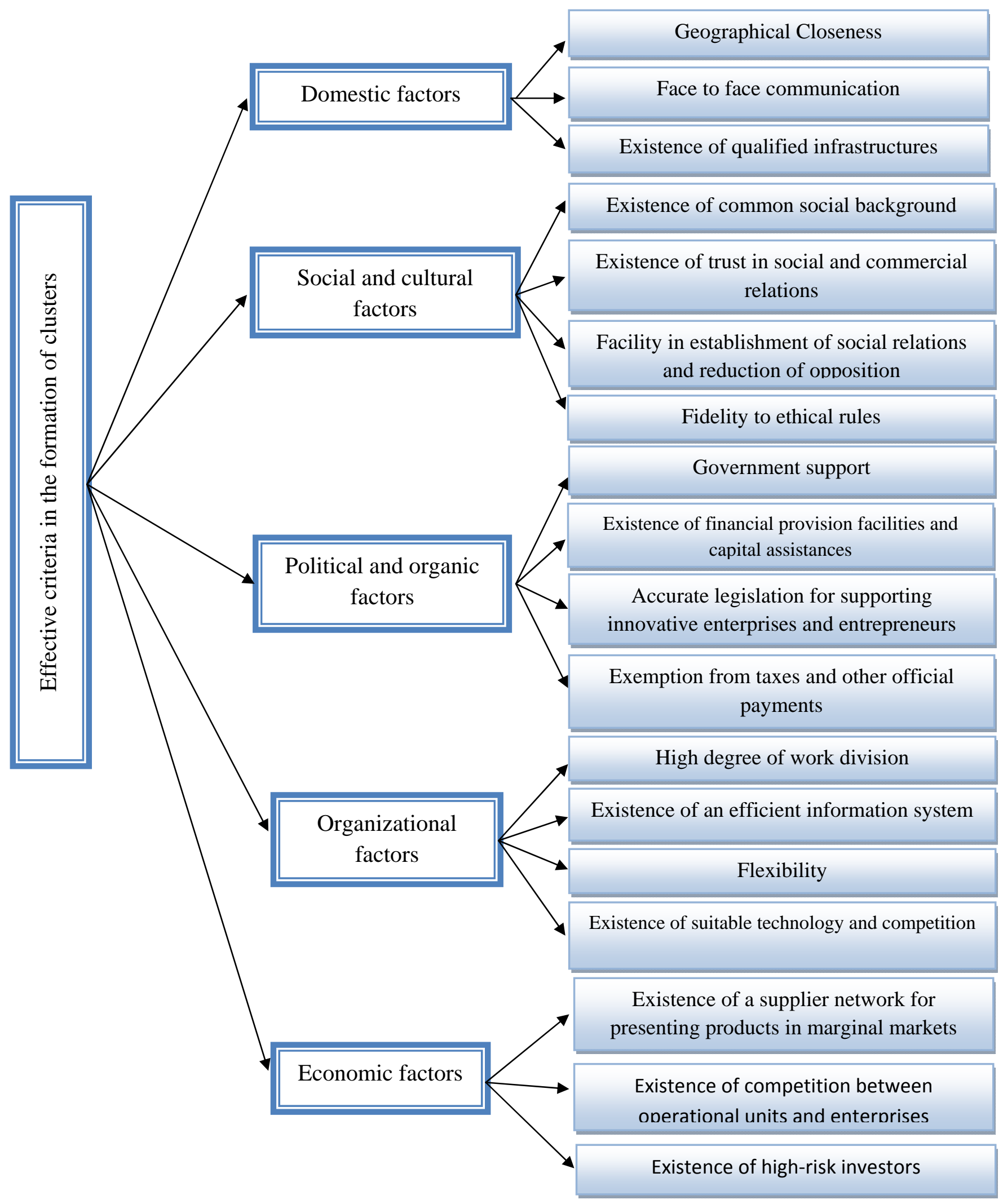

Fig. 1. Analytical network process for Industrial district 


\section{Analytical network process}

Analytical hierarchy process (AHP) is one of the widely used approaches for ranking problem with different criteria. There are several assumptions when AHP is applied to make decisions, such as, the independence between higher level elements and lower level elements, the independence of the elements within a level, and the hierarchy structure of the decision problem (Saaty, 1994, Saaty \& Zoffer, 2011). However, an obvious shortfall of AHP is the assumption of independency among various criteria. Analytic network process (ANP), on the other hand, captures interdependencies among the decision attributes and allows a more systematic analysis. In addition, the interactions of decision attributes within the same level and the feedbacks between two different levels are important issues, which that should be taken into consideration during the decision making process. Therefore, the AHP method does not work accurately when solving such decision problems (Saaty 1996). The analytical network process (ANP), as an extensive and complementary method of the AHP, was introduced and further developed by Saaty (1996; 1999; 2001; 2003; 2004; 2005; 2006; 2008). On the contrary to AHP, ANP provides a more generalized model in decision-making without making assumptions about the independency of the higher-level elements from lower-level elements and also of the elements within a level. Despite all these merits, the applications of ANP are not very common in a decision-making problem. However, in recent years, there has been an increase in the use of ANP in multi-criteria decision-making problems (Jharkhariaa \& Shankar , 2007).

The ANP method can be used to make decision problems, which cannot be structured hierarchically and does not contain the inner-independent and outer-independent assumptions. Since the introduction, the ANP method is applied to diverse areas. It also allows inclusion of all the relevant criteria including tangible or intangible, objective or subjective, etc. The ANP is the most comprehensive framework for the analysis of societal, governmental and corporate decisions that is available today to the decision makers. According to Chung et al. (2005), ANP has the following steps,

Step 1: Model construction and problem structuring: The problem should be stated clearly and decomposed into rational system like network. The structure can be obtained by the opinion of decision makers through brainstorming or other appropriate methods.

Step 2: Pairwise comparisons matrices and priority vectors: In ANP, like AHP, decision elements at each component are compared pairwise with respect to their importance towards their control criteria, and the components themselves are also compared pairwise with respect to their contribution to the goal.

Step 3: Super matrix formation: the super matrix concept is similar to the Markov chain process (Saaty 2005). To obtain global priorities in a system with interdependent influences, the local priority vectors are entered in the appropriate columns of a matrix. As result, a super matrix is actually a partitioned matrix, where each matrix segment represents a relationship between two nodes (components or clusters) in a system (Sarkis 2003).

\section{The results}

In this section, we present some of the necessary results for the implementation of ANP for prioritizing the criteria given in Fig. 1.

\subsection{Domestic factors}

In terms of domestic factors, we have considered three items of the existence of qualified infrastructure, face to face communication and geographical closeness and the normalized weights of 
these factors are $0.21898,0.22272$ and 0.55831 , respectively. In other words, geographical closeness is the most important factor, followed by face to face communication and qualified infrastructure.

\subsection{Social and cultural factors}

As we discussed, this items includes four sub-criteria, which include the existence of common social background, the existence of trust in social and commercial relationships, facility in establishment of social relationships and fidelity to ethical rules. The implementation of ANP to these factors yields 0.34823, $0.43546,0.13383$ and 0.08248 , for four mentioned sub-criteria, respectively. As we can observe, existence of trust in social and commercial relationships has been the most important factors followed by trust in social and commercial relationships and the other two factors are in the lower priorities.

\subsection{Political and Organizational factors}

The third main criteria is associated with political affairs, which includes four sub-criteria of Accurate legislation, Tax exemption and other official payments, existence of financial facilities and governmental support. The most important sub-criteria is government support with 0.43378 and the existence of financial support is the second important criterion with the weight of 0.32443 . The third important criterion is tax exemption with the relative weight of 0.16405 . Finally, the last criterion is accurate legislation with the weight of 0.07773 .

\subsection{Organization factors}

The fourth item is associated with organizational factor including four criteria, which are existence of an efficient information system, existence of suitable technology and competition, flexibility and high degree of work division. Among these factors, existence of suitable technology plays the most important role with the relative weight of 0.36117 , existence of an efficient information system is the second more important one with the relative weight of 0.34848 . The third important item is high degree of work division with the relative importance of 0.19440 and flexibility with relative importance of 0.09595 is the least important item.

\subsection{Economical factors}

The last main criteria, which influences our decision is associated with economical criterion. This item includes three criteria, including existence of a supplier network, existence of competition between operational units and existence of investor's with high risk. Among these items, existence of a supplier network with the relative importance of 0.54221 is the most important one, followed with the existence of competition between operational units with the relative importance of 0.31658 and the last item is the existence of high-risk investors with the relative importance of 0.14121.

\subsection{The relative importance of main criteria}

The last important step of ANP implementation is to determine the relative importance of five main criteria. In our calculations, domestic criterion is the most important item with the relative importance of 0.27129, political affairs is the second important factor with the relative importance of 0.20377. The third important item is economic factor with the relative importance of 0.18683 , organizational factor is the fourth item with the relative importance of 0.17743 , leaving social and cultural criterion as the least important item with the weight of 0.16068 .

\subsection{Final results}

Based on the results of the relative weights for different criteria, it is possible to calculate the final weights of all criteria. Table 1 shows details of ranking of all criteria. As we can observe from the results of Table 1, Geographical vicinity is the most important criterion by acquiring $11 \%$ of total 
weight. Existence of supplier network is the second most important item, which is estimated as $10 \%$ of the relative importance of the ranking. In addition, existence of trust in social and commercial relationships with about $8 \%$ of total weight comes into the third important item and other items are in other positions.

\section{Table 1}

Final weight of all criteria

\begin{tabular}{|c|c|c|c|}
\hline Title & Weight & Title & Weight \\
\hline Existence of supplier network & 0.54221 & High degree of work division & 0.19440 \\
\hline $\begin{array}{l}\text { Existence of competition among operational } \\
\text { units }\end{array}$ & 0.31865 & Accurate legislation & 0.16405 \\
\hline Existence of high-risk investors & 0.14122 & Tax exemption & 0.07773 \\
\hline Existence of suitable infrastructure & 0.21898 & Financial facilities & 0.32443 \\
\hline Existence of suitable structures & 0.22272 & Governmental support & 0.43378 \\
\hline Geographical vicinity & 0.55830 & Existence of trust & 0.43546 \\
\hline Existence of an efficient information system & 0.34848 & $\begin{array}{l}\text { Facility of establishment of social } \\
\text { relationships }\end{array}$ & 0.13383 \\
\hline $\begin{array}{l}\text { Existence of suitable technology and } \\
\text { competition }\end{array}$ & 0.36117 & Fidelity to ethical rules & 0.08248 \\
\hline Flexibility & 0.09566 & & \\
\hline
\end{tabular}

\section{Conclusion}

In this study, we discussed the importance of industrial cluster for the growth of economy in the world especially in developing countries. Next, we gathered experts' feedbacks on forming clustering in Iran's industries and, using analytical network process; we prioritized the relative importance of different factors and provided some necessary guidelines to develop clustering. The results of this paper indicated that the existence of a supplier network is the most important item, followed by the existence of competition among operational units, existence of high-risk investors and existence of suitable infrastructures. There are also other less important criteria including the existence of flexibility, suitable technology and competition, governmental regularities, social background, trust, etc.

\section{References}

Altenburg, T., \& Meyer-Stamer, J. (1999). How to promote clusters: Policy experience from Latin America. World Development, 27(9), 1693-1713.

Boari, C. (2001). Industrial clusters, focal firms and economic dynamism: A perspective from Italy. The World Bank.

Chung, S.H., Lee, A.H.I., \& Pearn, W.L. (2005). Analytic network process (ANP) approach for product mix planning in semiconductor fabricator. International Journal of Production Economics, 96 (1), 15-36.

Enright, M. J. (1996). Regional Clusters and Economic Development: A Research Agenda. In Business New works: Prospects for Regional Development. Edited by U.H. staber Et Al., Berlin, Walter De Gruyter.

Jharkharia, S., \& Shankar, R. (2007). Selection of logistics service provider: an analytic network process (ANP) approach. Omega 35, 274-289.

Nadvi, K. (1994). Industrial District Experiences in Developing Countries in UNCTAD, Technological Dynamism in Industrial Districts: An Alternative Approach to Industrialization in Developing Countries. New York and Geneva: United Nations.

NGA: National Governors Association (2002); A Governors Guide to Cluster - Based Economic Development. Washington, D.C. 20001-1512 WWW.nga.org.

Porter, M.E. (1985). Competitive Advantage, Macmillan, New York, Free Press.

Porter, M.E. (1990). The Competitive Advantage of Nations. New York: Basic Books. 
Porter, M.E. (1995). Competitive Advantage of the Inner City. Harvard Business Review, 55-71.

Porter, M.E. (1997). New strategies for Inner city economic. Development, Economic Development Quarterly, 11(1), 11-27.

Porter, M.E. (1998). Clusters and the New Economic of Competition. Harvard Business Review (November / December).

Porter, M. E. (2001) Clusters of Innovation: Regional Foundations of U.S. Competitiveness, Council on Competitiveness, Washington, Dc .Super Discussion Paper No. 00-39.

Porter, M.E, (2003a). The Economic Performance of Regions. Regional Studies, 37(6-7), 549-678.

Porter, M.E, (2003b). Building the Microeconomic Foundations of Competitiveness. in the Global Competitiveness Report 2002-2003, World Economic Forum, New York: Oxford University Press.

Pyke, F., \& Sengenberger, W. eds (1992) Industrial Districts and Local Economic Regeneration, Geneva: International Institute for Labor Studies (ILO).

Rabellotti, R. (1997). External Economies and Cooperation in Industrial Districts: A comparison of Italy and Mexico. Macmillan, London.

Rabellotti, R., \& Schmitz, H. (1997). The internal heterogeneity of industrial districts in Italy, Brazil and Mexico. IDS Working Paper, No. 59, Institute of Development Studies, University of Sussex, Brighton, forthcoming in Regional Studies.

Saaty, T.L. (1994). Fundamentals of the Analytic Hierarchy Process. RWS Publications, 4922 Ellsworth Ave., Pittsburgh, Pennsylvania.

Saaty, T.L. (1996). Decision Making with Dependence and Feedback: The Analytic Network Process. Pittsburgh, Pennsylvania: RWS Publications. ISBN 0-9620317- 9-8.

Saaty, T.L. (1999). Fundamentals of the analytic network process. ISAHP 1999, Kobe, Japan, August 12-14.

Saaty, T.L. (2001). Decision making with the analytic network process (ANP) and its Super Decisions Software: The National Missile Defense (NMD) Example, ISAHP 2001 Proceedings, Bern, Switzerland, August, 2-4.

Saaty, T.L. (2004). Fundamentals of the analytic network process: Dependence and feedback in decision-making with a single network. Journal of Systems Science and Systems Engineering, published at Tsinghua University, Beijing, Vol. 13, No. 2, pp. 129-157.

Saaty, T.L. (2005). Theory and Applications of the Analytic Network Process: Decision Making with Benefits, Opportunities, Costs and Risks. Pittsburgh, Pennsylvania: RWS Publications. ISBN 1888603-06-2.

Saaty, T.L. (2006). Rank from Comparisons and from Ratings in the Analytic Hierarchy/ Network Processes. European Journal of Operational Research, 168, 557-570.

Saaty, T.L. (2008). The Analytic Network Process. Iranian Journal of Operations Research, 1(1), 127.

Sarkis, J. (2003). Quantitative models for performance measurement systems alternate considerations. International Journal of Production Economics. 86 (1), 81-90.

Schmitz, H. (1995). Collective Efficiency: Growth Path for Small-Scale Industry. Journal of Development Studies, 31(4), 529-66.

Schmitz, H., \& Nadvi, K. (1999). Clustering and Industrialization: Introduction. World Development, 27(9), 1503-1514.

Scott, A. (1996). Regional motors of the global economy. Futures, 28 (5), 391-411. 